$\underline{\text { Original Article }}$

\title{
THE INFLUENCE OF VARIATION OF HYDROXYPROPYL METHYLCELLULOSE AND TWEEN 80 CONCENTRATIONS ON PHYSICAL CHARACTERISTICS AND PHYSICAL STABILITIES GEL OF WATER DRY EXTRACT OF TEMULAWAK
}

\author{
SEKAR AYU PAWESTRI ${ }^{1}$, TEUKU NANDA SAIFULLAH SULAIMAN ${ }^{2 *}$ \\ 1,2Faculty of Pharmacy, Universitas Gadjah Mada, Yogyakarta, Indonesia \\ Email: tn_saifullah@ugm.ac.id
}

Received: 12 Aug 2019, Revised and Accepted: 10 Oct 2019

\begin{abstract}
Objective: Water extract of temulawak (Curcuma xanthorrhizaRoxb.) contains curcumin, which known has antibacterial, antiinflammation, and antifungal activity so that it has potential used as wound healing. The purpose of this study was formulating gel of water extract of temulawak made by variation of hydroxypropyl methylcellulose (HPMC) and tween 80 concentrations and investigating the influence of formulations on physical
\end{abstract} characteristics and physical stabilities gel.

Methods: Gel was made by variation of HPMC and tween 80 concentrations (3,00\%: 1,00\%; 5,00\%: 1,00\%; 3,00\%: 2,00\%; 5,00\%; 2,00\%). Gel preparations was evaluated the physical characeristics by organoleptic test, homogeneity test, $\mathrm{pH}$, viscosity, spreadability, adhesiveness, and stability. The physical properties were analyzed by software Design Expert 9.

Results: The results showed that HPMC has dominant influenced on viscosity, spreadability, and adhesiveness. HPMC and tween 80 have not influence on organoleptic, homogeneity, and pH of the gel. Optimum formula is HPMC 5,00\% and tween $801,00 \%$. Optimum formula is stable on organoleptic, homogeneity, $\mathrm{pH}$, viscosity, and adhesiveness; however spreadability of gel is not stable during 3 mo storage.

Conclusion: Variation of HPMC and tween 80 concentrations influenced viscosity, spreadability, and adhesiveness, while they were not influenced on organoleptic, homogeneity, and pH of gel. HPMC had dominant influenced on viscosity, spreadability, and adhesiveness gel.

Keywords: Gel, Temulawak, Hydroxypropyl methylcellulose, Tween 80

(C) 2019 The Authors. Published by Innovare Academic Sciences Pvt Ltd. This is an open access article under the CC BY license (http://creativecommons.org/licenses/by/4.0/] DOI: http://dx.doi.org/10.22159/ijcpr.2019v11i6.36340

\section{INTRODUCTION}

Wound is damaged skin tissue which needed protection. Staphylococcus aureusis bacteria that often founded in wounded skin tissue. Infected burns have bacteria such asS. aureus, P. aeruginosa, and $E$. coli [1, 2]. Candida sp. is fungi that colonizes in burns [3]. Dried water extract of temulawak is a natural ingredient and contains curcumin, which has antibacterial and antifungal activity [4, 5]so it has potential as a wound medicine. Gel dosage form can facilitate the use of temulawak dried water extract as a wound medicine. Gel can retain and create a moist environment around the wound, which can accelerate wound healing [6].

In-gel preparations, it is necessary to choose the right gel base to obtain the expected gel properties. Temulawak dried water extract contains curcumin compounds which are unstable at alkaline $\mathrm{pH}$, so that it requires a gel base that can maintain the $\mathrm{pH}$ of curcumin to remain stable. Hydroxypropyl methylcellulose (HPMC) is a gel base that can produce a neutral, clear, and stable gel at $\mathrm{pH} 3-11$ so it is suitable as a base gel for maintaining $\mathrm{pH}$ of curcumin. Furthermore, HPMC provides a good film layer strength when it dries on the skin [7]. Dried water extract of temulawak is insoluble in water, so it is necessary to add surfactant to help them soluble in water. Surfactant has the ability as a wetting agent and solubilization of compounds in micelles from surfactants so that it can increase the solubility of compounds in water. Tween 80 is a surfactant used in formulas and is safe to use on the skin [8].

In this research, gel preparations were made from temulawak dried water extract using various concentrations of HPMC and tween 80, then the effect of variation of concentrations was observed on the physical properties of the gel. The gel was made using the Factorial
Design approach and the results of the physical properties of the gel were optimized with Design Expert 9. Physical stability testing with centrifugation was carried out on all four formulas, while the accelerated physical stability test was carried out for 3 mo on the optimum formula.

\section{MATERIALS AND METHODS}

\section{Materials}

Powder of Temulawak dried water extract (PT Phytochemindo Reksa), Methocel K15M (Colorcon), tween 80(PT Bratachem), metil paraben (PT Bratachem), aquadest (CV Genera Labora), and sweet orange essence (Tekun Jaya). All chemicals were purchased from Indonesia.

\section{Methods}

Specification of dried water extract of temulawak

Temulawak dried water extract was obtained from PT. Phytochemindo Reksa with specifications as listed in table 1.

\section{Preparation of gel}

Gel formulas can be seen in table 2. Gel was made by dispersion method: Aquadest was heated into $70^{\circ} \mathrm{C}$. HPMC was put into some hot distilled water, stirred until dissolved. Methylparaben was dissolved in a number of hot water and then put into the HPMC solution. Temulawak dried water extract was mixed with tween 80 and put some water into the extract-tween 80 mixture until dissolved, then the extract-tween 80 extracts were added to the HPMC solution. The mixture was stirred until homogeneous. Next, it was filled into a pot gel to be evaluated. 
Table 1: Specifications of dried water extract of temulawak

\begin{tabular}{|c|c|c|}
\hline \multicolumn{3}{|l|}{ Physicals-chemical data } \\
\hline Item & Standard & Result \\
\hline Appearance & Yellow-Brownish Yellow & Conform \\
\hline Mesh Size 80 & Min.90\% Pass & Conform \\
\hline Water (Karl Fischer) & Max. $10 \%$ & $2,01 \%$ \\
\hline Curcuminoid & $13-19 \%$ & $15,0 \%$ \\
\hline Volatile Oil & Min. $3 \%$ & $3 \%$ \\
\hline Heavy Metal & Max. 5 ppm & Conform \\
\hline Solubility & Partly soluble in Alcohol & Conform \\
\hline \multicolumn{3}{|l|}{ Microbiological data } \\
\hline Total Aerobic Bacteria & Max. $10^{4} \mathrm{cfu} / \mathrm{g}$ & Conform \\
\hline Fungi & Max. $10^{3} \mathrm{cfu} / \mathrm{g}$ & Conform \\
\hline E. Coli & Negative & Negative \\
\hline Staphylococcus A. & Negative & Negative \\
\hline Salmonella & Negative & Negative \\
\hline Pseudomonas aeruginosa & Negative & Negative \\
\hline
\end{tabular}

Table 2: Formula of temulawak dried water extract gel

\begin{tabular}{|c|c|c|c|c|}
\hline Materials (\%b/v) & Formula 1 & Formula a & Formula b & Formula ab \\
\hline Extract & 0,40 & 0,40 & 0,40 & 0,40 \\
\hline Tween 80 & 1,00 & 1,00 & 2,00 & 2,00 \\
\hline HPMC & 3,00 & 5,00 & 3,00 & 5,00 \\
\hline Metil Paraben & 0,10 & 0,10 & 0,10 & 0,10 \\
\hline Sweet Orange Essence & 0,03 & 0,03 & 0.03 & 0,03 \\
\hline Aquades ad & 100,00 & 100,00 & 100,00 & 100,00 \\
\hline
\end{tabular}

\section{Evaluation of physical properties of gel}

\section{Organoleptic}

Color, aroma, and gel texture were observed.

\section{Homogeneity}

A total of $0.1 \mathrm{~g}$ of gel was applied to the object-glass and observed under light. If the gel was well mixed and there were no coarse particles on the object-glass, the gel was homogeneous.

\section{pH}

$\mathrm{pH}$ paper strip was dipped for three seconds into the gel and was matched to the universal $\mathrm{pH}$ standard color ranges.

\section{Viscosity}

Viscosity of gel was observed using the rotor of equipment number 1 and 2 (depending on the thickness of the gel) and observed through the pointer until it stops stabilizing.

\section{Spreadability test}

A total of $0.5 \mathrm{~g}$ of gel was placed in the middle of the glass that had been given graph paper, covered with another glass that had been weighed and left for one minute, then measured the diameter of spreaded gel. Addition of 50, 100, 150, 200, and 250 grams of load per minute was conducted and then the diameter of spreaded gel was measured for each additional load.

\section{Adhesiveness test}

A total of $0.1 \mathrm{~g}$ of gel was placed on the glass of the object $(2 \times 2 \mathrm{~cm})$. The gel was placed on top of it with another object glass and given a load of $1 \mathrm{~kg}$ for $5 \mathrm{~min}$. The object-glass was then mounted on a sticky adhesiveness testing equipment that had been given a load of 80 grams. Time was recorded until the two glass objects were detached.

\section{Physical stability using centrifugation test}

A total of $2 \mathrm{~g}$ of gel was inserted into the conical, centrifuged at a speed of $3750 \mathrm{rpm}$ for $5 \mathrm{~h}$ and observed the phase separation that occurred.

\section{Optimum formula determination}

The result data on the physical properties of gel were analyzed using Design Expert 9 software to determine the optimum composition of HPMC and Tween 80.

\section{Optimum formula verification}

The result dataon the physical properties of the optimum formula that had been made was compared with the data predicted by Design Expert 9 software with a 95\% confidence level.

\section{Accelerated physical stability test of optimum formula}

The gels were stored with a temperature of $40{ }^{\circ} \mathrm{C} \pm 2{ }^{\circ} \mathrm{C} / 75 \% \mathrm{RH} \pm 5 \%$ RH for 3 mo and the physical properties of the gel were observed.

\section{Data analysis}

Data on gel physical properties were analyzed by Design Expert 9 to obtain the optimum formula. The optimum formula verification was conducted by comparing the data on the optimum physical properties of the experiment with the prediction of Design Expert 9 software. Data were analyzed for their normality with Saphiro-Wilk. Data that were normally distributed were analyzed by a one-sample t-test. Data that were not normally distributed used Mann-Whitney analysis. Meanwhile, data on gel physical stability for 3 mo were analyzed using a one-way ANOVA test if the data were normally distributed. Data that were not normally distributed were using the Friedman test.

\section{RESULTS}

The test results of the physical properties of the gel can be seen in table 3. The contour plot of gel physical properties shown in fig. 1 . The magnitude of the influence of each factor can be seen in table 4.

Table 3: Data of viscosity, spreadability, and adhesiveness of temulawak dried water extract gel

\begin{tabular}{llll}
\hline Formula & Viscosity (dPa. S) & Spreadability $\left(\mathbf{c m}^{2}\right)$ & Adhesiveness (seconds) \\
\hline 1 & $43,33 \pm 2,887$ & $57,42 \pm 3,525$ & $0,73 \pm 0,236$ \\
$\mathrm{~A}$ & $150,00 \pm 10,000$ & $32,77 \pm 4,693$ & $1,05 \pm 0,157$ \\
$\mathrm{~B}$ & $14,33 \pm 1,155$ & $83,10 \pm 17,031$ & $0,53 \pm 0,052$ \\
$\mathrm{Ab}$ & $80,00 \pm 0,000$ & $56,40 \pm 6,519$ & $0,79 \pm 0,046$ \\
\hline
\end{tabular}


$\mathbf{a}$
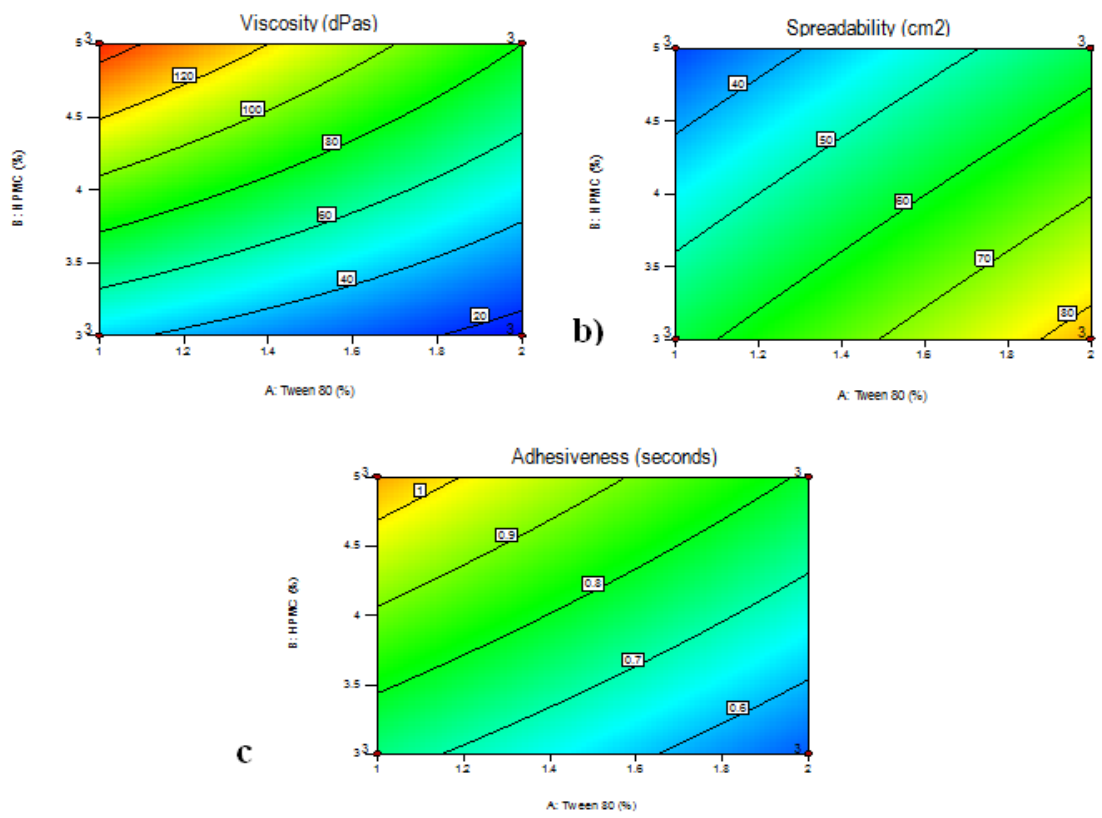

Fig. 1: Contour Plot a) Viscosity b) Spreadability c) Adhesiveness

Table 4: Data analysis on physical properties of temulawak dried water extract gel

\begin{tabular}{llll}
\hline Effect & Viscosity & Spreadability & Adhesiveness \\
\hline Tween 80 & $-47,83$ & 24,65 & $-0,23$ \\
HPMC & 84,50 & $-25,68$ & 0,29 \\
Tween 80 and HPMC & $-18,83$ & $-1,02$ & $-0,030$ \\
\hline
\end{tabular}

Response equation were below this:

Viscosity

$Y=71,08-23,92(A)+42,25(B)-9,42(A)(B) \ldots$ (1)

Spreadability

$\mathrm{Y}=57,42+12,33(\mathrm{~A})-12,84(\mathrm{~B})-0,51(\mathrm{~A})(\mathrm{B}) \ldots$ (2)

Adhesiveness
$Y=0,78-0,12(A)+0,14(B)-0,015(A)(B) \ldots$ (3)

Reference: $(\mathrm{A})=$ Tween $80(\mathrm{~B})=\mathrm{HPMC}$

Physical Stability of formula a and formula ab were stable after centrifugation. The criteria for determining the optimum formula can be seen in table 5. The results of the analysis using Design Expert 9 selected the highest desirability which was 0.841 . The optimum desirability formula graph can be seen in fig. 2 .

Table 5: Criteria determination of optimum formula

\begin{tabular}{llll}
\hline Response & Goal & Lower & Upper \\
\hline Spreadability & In range & 28,733 & 38,465 \\
Adhesiveness & Maximize & 0,47 & 1,16 \\
Viscosity & In range & 80,00 & 150,00 \\
\hline
\end{tabular}

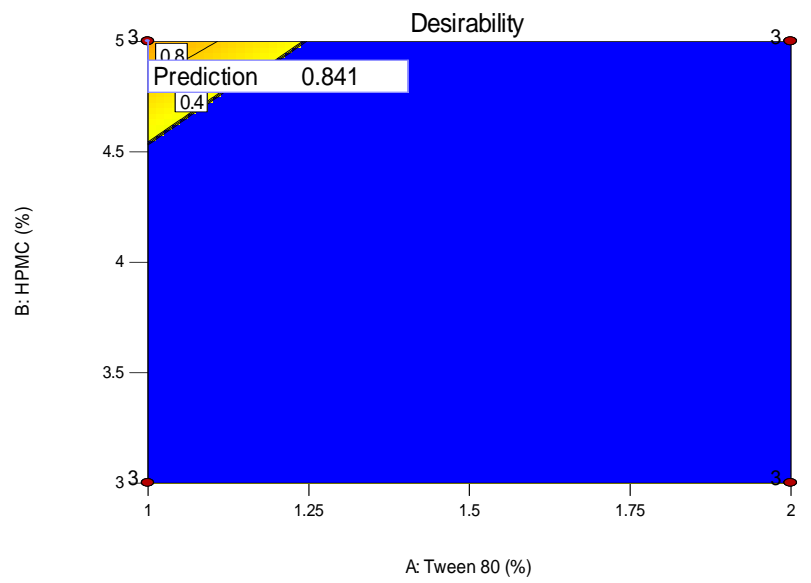

Fig. 2: Desirability graph of temulawak dried water extract optimum gel formula

Table 6: Comparison data of the prediction value and the actual value of the optimum formula 


\begin{tabular}{llllll}
\hline Response & Prediction & Actual & t-test & Sig (2 tailed) & Conclusion \\
\hline Spreadability & 32,77 & 30,51 & $-3,194$ & 0,086 & Different not significantly \\
Adhesiveness & 1,05 & 1,23 & 1,244 & 0,339 & Different not significantly \\
Viscosity & 146,67 & 150,00 & 0,577 & 0,622 & Different not significantly \\
\hline
\end{tabular}

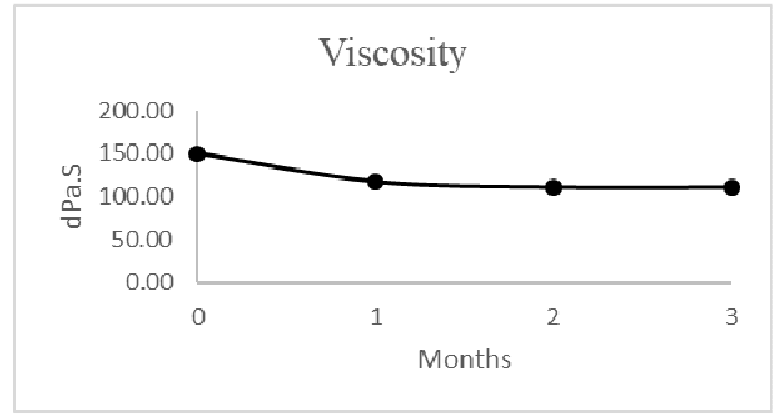

a)

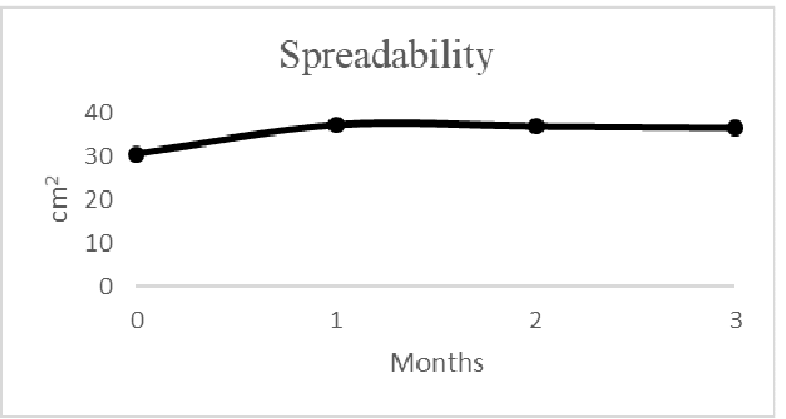

b)

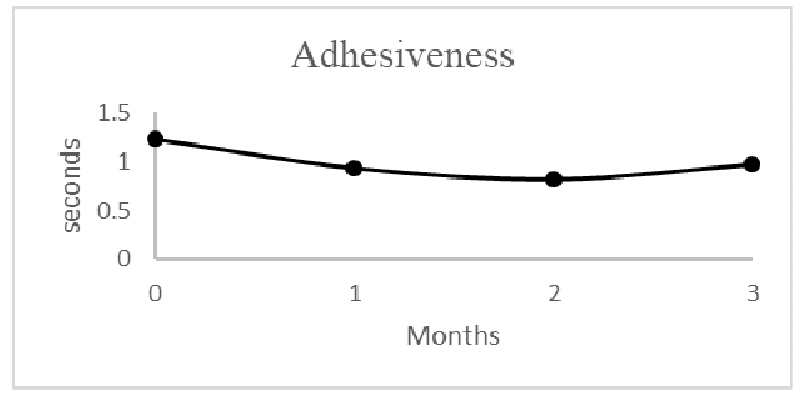

c)

Fig. 3: Stabilty graph of temulawak dried water extract optimum gel formula during 3 mo; a) Viscosity b) Spreadability c) Adhesiveness

The optimum formula chosen consisted of tween 80 at $1.00 \%$ and HPMC at $5.00 \%$. The verification results in table 6 showed that the results of the gel physical properties is not significantly different from Design Expert 9 predictions. The physical stability test of the optimum gel formula can be seen in fig. 3 .

\section{DISCUSSION}

The values of viscosity, spreadability, and adhesiveness vary from the four formulas indicating variations in the concentrations of HPMC and tween 80 affect the physical properties of the gel. The four gel formulas had almost the same organoleptic properties, which were yellow, orange-scented (given orange essence), gel-formed, and homogeneous. This shows that the variation of HPMC and tween 80 concentrations do not affect organoleptic properties and gel homogeneity.

The four gel formulas had a $\mathrm{pH}$ of 5 and were within the ideal $\mathrm{pH}$ range of the skin. This shows that the variation of HPMC and tween 80 concentrations does not affect the $\mathrm{pH}$ of the gel. HPMC is a nonionic polymer that cannot interact electrostatically with positive or negative charges in the gel formula [9], while tween 80 is also a nonionic surfactant that does not change the $\mathrm{pH}$ of the gel [10].

Gel viscosity is an important characteristic that determines the resistance of the flow of the gel formula so that the gel can spread well on the surface of the skin. The higher the viscosity of the gel, the longer the retention time of gel at the site of action. Tween 80 and the interaction between tween 80 and HPMC produced negative effect values on gel viscosity. This shows that the increase in the concentration of tween 80 in the formula will reduce gel viscosity. Tween 80 is a surfactant that has the ability to bind hydrophilic groups from water resulting in a decrease in interface tension of water phase so that causing a decrease in viscosity [11]. HPMC has the greatest effect value compared to the tween 80 effect and the interaction of both. This means that HPMC has a dominant effect in influencing gel viscosity.
The contour plot of gel viscosity in fig. 1 (a) shows that tween 80 affects the decrease in viscosity shown in the blue gradation area. The addition of HPMC resulted in an increase in viscosity which showed a change in color gradation from blue to bright green. The effect of HPMC is the greatest on gel viscosity. This is because gel viscosity is affected by the concentration of the polymer gelling agent. Increasing the concentration of the gelling agent will further strengthen the gel polymer network so that it can increase viscosity [12]. Hydrophilic polymers such as HPMC have the ability to increase the viscosity of the solution at low concentrations, to expand and absorb the surface. Polymers such as methylcellulose have at least 3 or 4 ether groups and 1 or 2 hydroxyl groups which can be widely hydrated by water. The oxygen ether has two free electron pairs which can bind two water molecules through hydrogen bonds. The result of increasing the size of the unit will increase resistance to flow or solution viscosity [13].

Spreadability of gel is an important characteristic for delivering the right dose to the target site, ease of applying it to the skin, and consumer acceptance. The higher the spreadability, the wider the contact gel above the skin surface. HPMC and the interaction of tween 80 and HPMC produced negative effects on spreadability. The increase in the HPMC concentration in the formula will reduce the spreadability of gel. HPMC has the greatest effect value compared to the tween 80 effect and the interaction of both. This shows that HPMC has a dominant effect in influencing the spread of gel.

The contour plot in fig. 1(b) shows that the greater the concentration of tween 80 will increase the spreadability shown in orange gradations. The addition of HPMC resulted in a decrease in spreadabilityindicated by changes color gradations from bright blue to dark blue. The effect of HPMC is the greatest on the spreadability of gel. This is because HPMC can increase gel viscosity associated with spreadability. The increasing viscosity, the resistance of fluid to flow is decreased, so that spreadability will decrease [14]. 
Gel adhesion is the ability of the gel to stick on the surface of the skin. Gel that has high adhesion, the gel will stick longer to the skin, so the delivery of active compounds is more optimal. Tween 80 and the interaction between tween 80 and HPMC produced a negative effect on gel adhesion. The increase in the concentration of tween 80 in the formula will reduce gel adhesion. HPMC has the biggest effect compared to tween 80 and the interaction of both. This means that HPMC has a dominant effect in influencing gel adhesion.

The contour plot in fig. 1(c) shows that the higher concentration of tween 80 will reduce adhesiveness indicated by changes in color gradation from bright blue to dark blue. The addition of HPMC resulted in an increase in adhesion which showed changes in the color gradation from green to orange. The effect from HPMC is the greatest on gel adhesion. This is because HPMC is a gel base that can increase viscosity which will prolong gel adhesiveness. The higher the concentration of the HPMC polymer, the higher the gel strength or adhesion.

The equation (1), (2), and (3) can be used to predict the composition of tween 80 and HPMC in gel preparation to produce the desired viscosity, spreadability and adhesiveness response of the gel.

Formula a and formula ab were stable after centrifugation because the higher concentration of HPMC makes the bond between particles in the gel system stronger so that the separation becomes smaller. The optimum formula of the gel was yellow, orange-scented, gel form, homogeneous and had $\mathrm{pH}$ value 5 for 3 mo. It means organoleptic properties and $\mathrm{pH}$ of the gel were stable during storage. The results of the analysis for viscosity and adhesiveness were stable, but the analysis for spreadability had significant differences during storage. This might be due to the viscosity was decreased during storage so that it also affects the spreadability which will increase too.

\section{CONCLUSION}

Variation of HPMC and tween 80 concentrations influenced viscosity, spreadability, and adhesiveness, while they were not influenced on organoleptic, homogeneity, and $\mathrm{pH}$ of gel. HPMC had dominant influenced on viscosity, spreadability, and adhesiveness gel. Optimum formula of gel HPMC 5, 00\% and tween 80 1,00\%. Formula a and formula ab were stable physically after centrifugation. The optimum formula were stable on organoleptic, homogeneity, $\mathrm{pH}$, viscosity, and adhesiveness; however spreadability of gel was not stable during 3 mo storage.

\section{ACKNOWLEDGMENT}

We would like to thank the technicians of the Formulation Technology Laboratory for their help in providing laboratory equipment usage instructions for this research.

\section{AUTHORS CONTRIBUTIONS}

All the author have contributed equally.

\section{CONFLICT OF INTERESTS}

Declare none

\section{REFERENCES}

1. Bowler PG, Duerden BI, Armstrong DG. Wound microbiology and associated approaches to wound management. Clin Microbiol Rev 2001;14:244-69.

2. Posluszny JA, Conrad P, Halerz M, Shankar R, Gamelli RL. Surgical burn wound infections and their clinical implications. J Burn Care Res 2011;32:324-33.

3. Cancio LC, Howard PA, McManus AT, Kim SH, Goodwin CW, BA Pruitt J. Burn wound infections [Internet]. Zuckschwerdt Tersediapada; 2001. Available from: https://www.ncbi.nlm.nih.gov/books/NBK6970/ [Last accessed on 23 Sep 2018]

4. Gunes H, Gulen D, Mutlu R, Gumus A, Tas T, Topkaya AE. Antibacterial effects of curcumin: an in vitro minimum inhibitory concentration study. ToxicolInd Health 2016;32:246-50.

5. Neelofar K, Shreaz S, Rimple B, Muralidhar S, Nikhat M, Khan LA. Curcumin as a promising anticandidal of clinical interest Can J Microbiol 2011;57:204-10.

6. Boateng JS, Matthews KH, Stevens HNE, Eccleston GM. Wound healing dressings and drug delivery systems: a review. J Pharm Sci 2008;97:2892-923.

7. Rogers T. Hypromellose. Dalam: Handbook of Pharmaceutical Excipients. 6 ed. London: Pharmaceutical Press. Inc; 2009.

8. Williams AC, Barry BW. Penetration enhancers. Adv Drug Delivery Rev 2004;56:603-18.

9. Pongjanyakul T, Kanjanabat S. Influence of $\mathrm{pH}$ modifiers and HPMC viscosity grades on nicotine-magnesium aluminum silicate complex-loaded buccal matrix tablets. AAPS PharmSciTech 2012;13:674-85.

10. Fasolin LH, Picone CSF, Santana RC, Cunha RL. Production of hybrid gels from polysorbate and gellan gum. Food Res Int 2013;54:501-7.

11. Naiya TK, Kumar R, Mohapatra S, Mandal A. Studies on the effect of surfactants on rheology of synthetic crude. J Pet Sci Res 2014:1-7. Avalaible from: http://dpijournals.com/index.php/JPSR/article/view/1009. [Last accessed 23 Sep 2018]

12. Garg A, Aggarwal D, Garg S, Singla AK. Spreading of semisolid formulations: an update. Pharm Technol North Am 2002;26:84-105.

13. Sinko PJ. Martin's physical pharmacy and pharmaceutical sciences. Sixth, North American edition. Baltimore, Lippincot William and Wilkins; 2010.

14. Swastika A, Mufrod M, Purwanto P. Antioxidant activity of cream dosage form of tomato extract (Solanumlycopersicum L.). Traditional Med J 2015;18:132-40. 